\title{
Comprensión de textos discontinuos: caricatura y afiche
}

Artículo de reflexión

Fecha de Recepción: 2 julio 2018

Fecha de Aprobación: 14 noviembre 2018

\author{
Dora Cecilia Cristiano Ojeda* \\ Liceth Yadira Chaparro Merchán** \\ Nidia Milena Enciso Rodríguez ${ }^{* * * *}$
}

\section{Resumen}

Este manuscrito da cuenta de los avances de la investigación "Comprensión de textos discontinuos: caricatura y afiche". La revisión teórica toma como base la aplicación del modelo pragmático de Sperber y Wilson. El propósito se enmarca en fortalecer la habilidad crítica para traer el significado de un texto discontinuo, específicamente la caricatura y el afiche, para potenciar la comprensión textual. Esta investigación se llevó a cabo con los grados $4^{\circ}, 8^{\circ}$ y $10^{\circ}$, partió de una fase exploratoria, teniendo en cuenta las etapas de la investigación acción y acudiendo a la aplicación de un ejercicio consistente en analizar una caricatura y un afiche. En el afiche para ellos es de gran importancia el texto, por cuanto agrega y complementa la información, mientras que en la caricatura, se evidenciaron diversas interpretaciones, de acuerdo con los detalles observados por cada uno, algunos dieron una interpretación adecuada y otros inadecuada, pero cada uno recibió el mensaje transmitido y destacaron algún aspecto de acuerdo con sus conocimientos previos o con su propia experiencia, por cuanto emitieron juicios de acuerdo con su pensamiento crítico y creativo, identificaron argumentos y supuestos, realizaron inferencias, y dedujeron conclusiones, desarrollando las competencias comunicativas desde la perspectiva social y cultural.

Palabras clave: Textos, caricatura, competencia, comunicación, discontinuos, comprensión, lectura crítica, modelo pragmático.

\footnotetext{
* Institución Educativa Técnico Francisco José de Caldas Socotá - Boyacá Colombia cecicriojeda1@gmail.com ** Institución Educativa Técnico Francisco José de Caldas Socotá - Boyacá Colombia lycuptc@hotmail.com *** Institución Educativa Técnico Francisco José de Caldas Socotá - Boyacá -

Colombia milenaenciso11@gmail. com
}

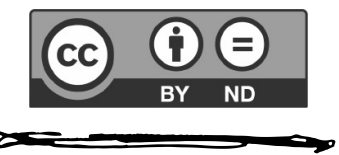


Castro, Gómez \& Prieto

(2016), en el estudio titulado

"elementos para el análisis de imágenes para llegar a la lectura inferencial y crítica”.

\section{Introducción}

Para comenzar se presentan los estudios realizados que de alguna manera están relacionados con el proyecto de investigación. En el ámbito internacional se parte del estudio por Urrutia \& García (2013), titulado: "evaluación de la comprensión lectora en alumnos de primer y tercer curso de secundaria”, tuvo como propósito evaluar la comprensión lectora de alumnos de primer y tercer año de secundaria de un instituto público. Los resultados demuestran que se encontraron diferencias significativas entre los alumnos de primer y tercer nivel en la comprensión lectora; sin embargo, ambos cursos presentaron un bajo rendimiento lector en los textos discontinuos en relación con los continuos. Aspectos como la integración de conceptos no mejoran significativamente de un nivel a otro. Este trabajo aporta a la presente investigación sustentos teóricos referidos al análisis de textos discontinuos como un proceso lector, más exigente y que incitan al lector a la construcción de significados propios.

Por otro lado, la investigación realizada por Arias (2011), titulada: "Estrategias cognitivas orientadas a los procesos de inferencia en el desarrollo de la lectura de alumnos del V y VI ciclos de educación básica regular”, estuvo orientada a proponer módulos de lecturas con sus respectivas estrategias inferenciales, las cuales garantizarían una sólida lectura comprensiva. La investigación permitió validar módulos utilizando textos discontinuos elaborados para los niveles de $\mathrm{V}$ y VII. Por tanto, los sustentos teóricos referidos a la comprensión de las categorías y componentes de los textos discontinuos para la aplicación del modelo pragmático, son aportes valiosos para el presente desarrollo investigativo.

De modo similar, en el orden nacional Narváez (2016), realizó la investigación "competencias comunicativas y lectura crítica: una relación ineludible" que tuvo como propósito identificar el nivel de las competencias interpretativa, argumentativa y propositiva en los estudiantes de décimo grado de la Institución Educativa Normal Superior de Corozal - Sucre, para luego determinar la relación existente entre las competencias comunicativas y la lectura crítica. Los resultados indican que existe una relación directa moderada entre lectura crítica y las competencias comunicativas propositiva y argumentativa. Sin embargo, entre lectura crítica y competencia interpretativa la relación es directa alta. Considerando los sustentos teóricos referidos a la lectura crítica como un aspecto fundamental dentro de la investigación en curso.

Por otra parte, los autores Castro, Gómez \& Prieto (2016), en el estudio titulado "elementos para el análisis de imágenes para llegar a la lectura inferencial y crítica". Tuvo como objetivo fundamental contribuir con el fortalecimiento en los niveles de lectura inferencial y crítica por medio de elementos para el análisis de imágenes. El proceso investigativo 
concluye que trabajar en el aula de clase con textos discontinuos en un espacio universitario trae consigo muchos retos en cuanto a planeación pedagógica, pero a partir de los conceptos manejados por Acaso (2009) y Eisner (1995), quienes por medio de sus investigaciones aportan una información significativa sobre lectura de imágenes en textos discontinuos, permitieron hacer un uso valioso en cuanto a su contenido para el aprovechamiento de este tipo de textos. Los estudiantes que participaron en el proceso de implementación, mostraron avances significativos en lectura inferencial y crítica, que permiten afirmar que el modelo de análisis es apropiado.

Además, se tomarán los aportes en desarrollo metodológico del trabajo realizado por Forero, Herrera \& Narváez (2015), "El Manga, una herramienta didáctica en los procesos de lectura", para fomentar la lectura de los estudiantes del tercer ciclo de educación básica por medio del Manga (texto discontinuo). Los resultados permitieron concluir que con El Manga se pueden adaptar las didácticas en torno a la lectura, ya que es una propuesta que busca fortalecer los procesos del aprendizaje por medio del aprovechamiento de sus recursos didácticos, y a su vez implementa los textos discontinuos (visual) en el área de lengua castellana. Esta propuesta no tiene como propósito llamar la atención del estudiante con imágenes sin sentido, sino al contrario enlazar esas imágenes con el fin de fortalecer las debilidades en la lectura y en la producción textual en el área de lengua castellana. Este trabajo aporta a la presente investigación sustentos teóricos referidos a la importancia de implementar el estudio de los textos discontinuos en el área de lenguaje con el fin de fortalecer las dificultades en el proceso lector.

En relación con los sustentos teóricos, es preciso denotar que la caricatura y el afiche como textos discontinuos sirven como herramienta para analizar e interpretar elementos culturales y sociales que van ligados dentro del proceso formativo, en este caso evaluadas dentro de las pruebas saber de lenguaje para identificar el nivel de desarrollo de las habilidades comunicativas en el proceso lector, cuando utilizan el lenguaje para expresar lo que piensan a partir de los conocimientos previos adquiridos.

Con respecto a la comprensión de textos discontinuos se puede señalar que la lectura en el aula debe abordar diversidad de textos, así como los gráficos (caricaturas, comics, afiches, avisos), tablas, mapas, que permiten un estímulo efectivo de carácter lingüístico, que pone en marcha de manera automática diferentes tipos de procesos, lo que favorece el aprendizaje sobre los mecanismos que dan coherencia y cohesión a los textos y a la elaboración de esquemas conceptuales para la interpretación.

El proyecto de investigación surge a partir del análisis de los resultados obtenidos en las pruebas Saber de la institución las cuales arrojaron el aumento del nivel insuficiente en el área 
de lenguaje en primaria y secundaria, dado que los estudiantes presentan dificultades en la comprensión lectora, siendo pertinente la aplicación del proyecto con el objetivo de fortalecer el nivel crítico de los estudiantes y mejorar los resultados de las pruebas.

En este sentido es pertinente resaltar que el propósito de la investigación pretende fortalecer el proceso lector en los grupos intervenidos $4^{\circ}, 8^{\circ}$ y $10^{\circ}$ donde se espera obtener una reflexión producto de los criterios concertados dentro del plan de acción y a su vez potenciar la capacidad de análisis de los educandos al enfrentarse a pruebas externas e internas y de esta manera lograr un cambio significativo en el proceso lector indispensable en la comprensión lectora.

El proyecto de investigación que se está desarrollando aplica y adecua el modelo pragmático de Sperber \& Wilson (2004) quienes, de manera sintética, indican que en un proceso de comunicación hay un emisor que quiere influenciar o incidir en el receptor mediante una serie de comportamientos ostensibles, que en conjunto se denominan ostensión; para este propósito, puede utilizar códigos verbales y no verbales de manera sistémica, lo que se denomina en el modelo, codificación. Desde de la perspectiva del receptor, quien percibe el texto discontinuo, este inicia un proceso de lectura del sistema de códigos propuesto por el productor del texto, a este proceso se le llama decodificación. En el caso específico, para decodificar textos discontinuos desarrolla un proceso de relación e implicación de los códigos manifiestos o implícitos, seleccionando lo relevante dejando en un segundo plano elementos poco significativos, infiriendo, hasta acercarse a la ostensión que ha dejado latente o tácito el emisor.

La metodología utilizada en la investigación es de carácter cualitativo, (Sandín, 2003), definida como una "actividad sistemática orientada a la comprensión en profundidad de fenómenos educativos y sociales, a la transformación de prácticas y escenarios socio educativos"(p.18). Así mismo por la necesidad de comprender la práctica social en la que se pretende actuar se toma el paradigma Históricohermenéutico, (Cifuentes, 2011), desde esta perspectiva "busca reconocer la diversidad, comprender la realidad; construir sentido a partir de la comprensión histórica del mundo simbólico"(p. 30). Lo que significa que auspicia la apertura a la subjetividad de los actores sociales al reconocer y valorar otras racionalidades, puesto que se centra en los estudiantes sujetos de la investigación y que desde el escenario áulico permite analizar las diferentes prácticas y experiencias con la lectura y el significado que está tiene al trascender en el conocimiento, de este modo convergen las realidades de la interacción de los estudiantes con la lectura a través de textos discontinuos, por ello el modelo pragmático de la relevancia de Sperber \& Wilson (2004), se ajusta y ofrece un aporte importante en la comprensión lectora que intenta explicar cuándo y cómo el receptor interpreta el lenguaje visual para transformarlo en lenguaje verbal 
de acuerdo a la interacción social y sus conocimientos previos.

De esta manera para la aproximación a la realidad se toma la investigación - acción de (Elliott, 1993), quien afirmó que "es un estudio de una situación social con el fin de mejorar la calidad de la acción dentro de la misma”. (p.4). Mediante esta investigación acción, el docente orienta su actuación para mejorarla a partir de la reflexión y la relación de los procesos concretos en los escenarios del aula, para ello plantea tres fases, planeación, acción y evaluación, cada una de ellas con aspectos específicos que proveen al investigador una secuencia coherente de la metodología y técnicas que permiten poner en marcha el plan y evaluarlo sucesivamente.

Los resultados de la investigación contribuyen no solo al fortalecimiento de la lectura crítica y el desarrollo de las competencias comunicativas en los estudiantes para atender la problemática, sino también propone sugerencias a la práctica docente para abordar la comprensión lectora desde la perspectiva social que se relaciona con el conocimiento del medio cultural donde el sujeto aparece con distintas demandas y condiciones como lector.

El artículo comprende un informe de los avances de la investigación y contiene en la primera parte la introducción que engloba el problema, el marco teórico, los objetivos; seguido por la metodología, los resultados y las conclusiones.

Por otro lado, en el artículo se presenta un ejemplo de una caricatura y un afiche socializando la aplicación del modelo de la relevancia que tiene en cuenta los componentes o categorías: codificación, decodificación, ostensión, relevancia e inferencia, y cómo los estudiantes a través del análisis de estos textos discontinuos fortalecen el proceso lector al enfrentarse a pruebas que miden la competencia lectora y llegar al nivel de lectura crítica.

\section{Ejes teóricos}

Los textos discontinuos presentan información en forma no lineal $y$ no secuencial y requieren de un tratamiento que analice detalladamente los componentes explícitos e implícitos para su mejor comprensión, además tienen una función social que se convierte en una herramienta portadora de mensaje y brinda la posibilidad de interactuar con el texto, pues en este caso la caricatura y el afiche en su riqueza gráfica motiva al lector a incluirse dentro de un proceso de lectura más profundo.

Modelo pragmático. Teoría de la relevancia de Sperber y Wilson. Uno de los sustentos teóricos que se toman como base fundamental está en la teoría de relevancia de Sperber \& Wilson (2004), dentro de un modelo pragmático que se propone explicar el modo en que los hablantes interpretan los enunciados, a su vez parten de la base que comunicar consiste en atraer la atención del receptor. Para ello, tanto el emisor como el receptor conducen su atención a la información que consideren más relevante para un efecto mayor utilizando el menor esfuerzo en el proceso lector. Por su
Los textos discontinuos presentan información en forma no lineal y no secuencial y requieren de un tratamiento que analice detalladamente los componentes explícitos e implícitos para su mejor comprensión, 
parte, el emisor efectúa la ostensión con el fin de llamar la atención del receptor quien infiere el contenido del mensaje de acuerdo con la trascendencia que tenga para él.

De acuerdo con lo anterior ser relevante significa favorecer la relación entre el enunciado y el contexto, es decir el enunciado como tal desde sus elementos y el receptor quien procesa la información para dar sus premisas de lo que ha interpretado, entendido el contexto desde un modo físico y lingüístico, partiendo de los saberes previos que el receptor posee y que ha construido desde sus experiencias comunicativas que ha ido elaborando consecuentemente en el proceso educativo.

Según la teoría de la relevancia, la comunicación está cimentada en el uso de componentes que van ligados para lograr un efecto relevante en el proceso lector: codificación y descodificación y otro la ostensión e inferencia. La codificación establece los elementos que aportan para conocer lo que dice el texto, la descodificación involucra el modo en cómo se da la información que es interpretada a manera de premisas por el receptor, para continuar con un proceso de ostensión que se logra a partir de lo que quiere decir o lo que pretende el texto, identificando la relevancia de los puntos fundamentales del texto atrayendo la atención del receptor quien por medio del proceso inferencial interpreta el contenido reconociendo la importancia del mensaje.
Textos discontinuos. Dentro del aprendizaje para el desarrollo de una competencia lectora en un ámbito escolar, el estudio de los textos discontinuos no es tan relevante porque se tiene la concepción de relegar el estudio a solos textos continuos dejando atrás la importancia de su análisis el cual es más disiente por su forma y contenido. Para tener en cuenta su pertinencia las pruebas externas como PISA, INEE (2012) menciona que "Los textos discontinuos resultan fundamentales para desarrollar prácticas sociales del lenguaje en los diversos ámbitos de la vida contemporánea, regida por un uso cada vez más especializado de todos los tipos y formatos textuales”. (p 6.)

La lectura de textos con este formato supone el empleo de los procesos cognitivos de identificación, interpretación y reflexión de información en textos que pueden resultar poco familiares para los estudiantes, por ejemplo, las caricaturas y afiches implica el conocimiento de convenciones culturales que no siempre resultan claras ni fáciles de manejar para los estudiantes o lectores en general. Este formato se trabaja tradicionalmente poco en la escuela, pero en el presente ha ido adquiriendo una importancia e interés progresivos, vinculados con el flujo constante $y$ creciente de información fragmentada que caracteriza a nuestra sociedad actual.

Los textos discontinuos seleccionados para el desarrollo de la investigación son las caricaturas y afiches que por su contenido gráfico, simbólico 
e informativo posibilitan una interpretación de sus elementos tanto implícitos como explícitos. En este sentido es pertinente resaltar que la caricatura como género artístico es un tipo de representación de hechos para transmitir un mensaje, que en la mayoría de las veces en forma satírica representa una situación determinada; resultando a su vez un instrumento valioso y necesario para la reflexión y el análisis, por lo cual es necesario identificar elementos manifiestos como: las emociones, el contexto, la forma, el espacio, el lenguaje y la intención del mensaje, entre otros. Mientras que la intención de la caricatura va más allá de las representaciones gráficas, para lograr lo verdaderamente característico de lo que quiere decir y por su naturaleza satírica capta la atención de los receptores, ya que suscita humor e interés en el estudio de textos de forma discontinua.

Atendiendo esas consideraciones, la caricatura "es un dibujo por el cual se pretende ridiculizar a una persona, un objeto o una situación. Este propósito se logra, la mayoría de las veces, exagerando los rasgos físicos de las personas u objetos representados" (Muñoz, 2012).

La caricatura está siempre vinculada al humor. El efecto cómico que suscita, es el resultado de un conflicto entre lo real y lo irreal, un conflicto en el que se exageran las situaciones. (León, 2006 p.68). Igualmente, este tipo de texto es utilizado en la crítica social, ya que es un excelente medio de expresión; pues el dibujo cómico puede representar todo tipo de conflictos humanos y dada su enorme capacidad de anuncio como modo de entretenimiento, la caricatura se ha convertido en un símbolo de la cultura actual. Baudelarie (1989) afirma que "la caricatura es un elemento de poder en base a la reflexión sobre lo cómico como un elemento que indica superioridad, basando sus reflexiones en una concepción histórica de la risa como expresión condenable y primitiva".

Por lo tanto, una caricatura es una pequeña obra de arte de carácter satírico. Esto quiere decir que su propósito fundamental es ridiculizar personas o situaciones. Toda caricatura es satírica por naturaleza. El efecto cómico surge a partir de una oposición inesperada. Lo que se considera normal o habitual sirve de fuente para constituir aquello que lo transgrede. De tal forma que el desconcierto que produce contemplar una contradicción de este tipo provoca risa. Sin embargo, no en todas las caricaturas se utiliza la exageración o deformación de rasgos para suscitar emociones en las personas.

Por otro parte, al igual que la caricatura, el afiche como texto discontinuo constituye una gama de posibilidades por su combinación perfecta entre lo lingüístico y lo no lingüístico, su objetivo es que oriente la atención de quien lo observa por sus elementos pictóricos generalmente exhibidos como recursos publicitarios para un grupo determinado; su contenido tiene información expuesta que amplía el sentido global de lo representado. Es un tipo de texto que divulga un 
mensaje visual que promueve la participación interactiva entre el emisor y el receptor con el propósito de que la información dada cumpla con la intención comunicativa. En este sentido Eisner (1995), afirma que "en el desarrollo de las capacidades para la apreciación necesaria en la percepción estética de la imagen y comprender e interpretar, se requiere atender lo productivo, crítico y cultural” (p.5). De tal manera que la adquisición de constancias visuales permite al individuo descubrir la forma analítica, el carácter expresivo de la forma visual, por lo tanto, experimenta la naturaleza sensible mediante su percepción.

Según Hutchinson, Harold (1968). "Un afiche, es en esencia, un anuncio grande por lo común cuenta con un elemento pictórico, está impreso en papel y es exhibido en una pared o en una cartelera en la vía pública para el público en general”. Su objetivo es que el caminante oriente su atención a lo que se pretende promocionar y que así le quede grabado algún mensaje. El elemento de carácter visual llamará la atención, y debe ser lo suficientemente llamativo para impactar al transeúnte; suele tener un texto que complementa la información expuesta para ampliar el sentido global que ofrece este tipo de texto.

El afiche como expresión crítica se vale de elementos implícitos y explícitos que le permiten al observador ser agente activo e intérprete, pues este tipo de textos conduce a la transformación de la información en conocimiento, sin obviar el factor estético que cautiva la atención del receptor, por su parte elementos como: la imagen, el texto o el esquema dependen de la intención del emisor al diseñar el afiche.

Estos recursos didácticos, por su estructura, composición y temática permiten fortalecer un proceso lector más complejo como la lectura crítica, que es uno de los aspectos primordiales dentro del contexto académico debido a su componente social que no es ajena a la realidad del estudiante, por ello, este tipo de formato hace parte de las pruebas externas e internas en las diferentes áreas del saber y desarrolla la competencia lectora dentro de los planos literal, inferencial y crítico, además promueve la participación activa de los estudiantes ya que ellos expresan sus opiniones y reflexiones sobre los textos dados.

Por otra parte, hoy en día se busca que los estudiantes desarrollen un alto nivel de comprensión lectora para que puedan ser sujetos activos de la sociedad que los rodea a través del análisis de lecturas que aporten significativamente en su rol de educando. Por esta razón, la lectura crítica aborda temas sociales para que no se vuelvan ajenos a la realidad de los que hacen parte de un contexto académico. Con base en los lineamientos curriculares "La lectura crítica es un modo de lectura superior, que demanda de cualquier persona una mayor exigencia. Su importancia radica en que la comprensión de muchos de los textos de una sociedad (académicos, periodísticos, políticos, etc.) exigen de este tipo de lectura, por ello, hace parte de las pruebas evaluables por 
el Instituto Colombiano para la Evaluación de la Educación (ICFES) para los estudiantes que egresan del bachillerato y de la educación superior colombiana.” (p.3)

La lectura crítica como un proceso crucial en el desarrollo de la competencia lectora y escritora, así como lo menciona Cassany (2006) "la lectura crítica es un tipo complejo de lectura que exige niveles más altos de comprensión y a su vez requiere de los planos previos de comprensión (literal, inferencias, intenciones, etc.) del texto, y exige una suerte de respuesta personal externa del lector frente al texto (frente a su contenido, intención, punto de vista, etc.)”.(p.52)

Por consiguiente, la lectura crítica se basa en un proceso de estudio continuo gradual y de pretensión en la que se requiere tener la capacidad de decodificar el contenido del texto para su posterior análisis, entendido como la interpretación de todos los elementos de forma y de contexto incluidos en las lecturas.

Según el módulo de lectura crítica Saber Pro 2014 el propósito de las pruebas ICFES es que el estudiante cuente con una comprensión lectora que le permita analizar, comprender y tomar posturas críticas frente a un texto, desarrollando competencias propias del pensamiento crítico, las cuales se relacionan de la siguiente manera:

\section{Competencias lectura crítica}

1. Identificar y entender los contenidos locales que conforman un texto. Esta competencia abarca los elementos explícitos del texto que dan cuenta de los componentes particulares que componen un texto.

2. Comprender cómo se articulan las partes de un texto para darle un sentido global. Esta competencia encuentra elementos semánticos en común que se asocian entre sí para dar un significado global.

3. Reflexionar a partir de un texto y evaluar su contenido. Esta competencia relaciona el significado adquirido con las apreciaciones personales de forma crítica, valida y concisa, generando implicaciones, supuestos e inferencias que enriquecerán el proceso lector. Rojas (2014) citado por ICFES.

Materiales y métodos. El desarrollo metodológico estará orientado por la investigación acción, la cual tiene como propósito mejorar la práctica educativa, a partir de la reflexión docente y visto desde la perspectiva de Elliott (1991), "es una investigación que pretende mejorar la educación cambiando prácticas y que permite aprender gracias al análisis reflexivo de las consecuencias que genera; es participativa y colaboradora.” (p27.) La aplicación de este tipo de investigación genera que los actores educativos analicen críticamente la situación investigada; en este caso mejorar el nivel de comprensión de lectura crítica en los estudiantes, además permite justificar la labor educativa reivindicando su papel fundamental dentro del proceso de formación pedagógica, así como lo menciona Elliot (1991), "el objetivo principal de la investigación acción "la lectura crítica es un tipo complejo de lectura que exige niveles más altos de comprensión y a su vez requiere de los planos previos de comprensión (literal, inferencias, intenciones, etc.) del texto, y exige una suerte de respuesta personal externa del lector frente al texto (frente a su contenido, intención, punto de vista, etc.)" 
no es la producción de conocimientos sino la mejora de la calidad educativa" (p.34), por lo tanto, el docente en su papel de investigador debe fomentar cambios significativos en el aula.

Para explicar el proceso de la investigación y teniendo en cuenta su origen y desarrollo la actividad investigativa, se indica que ésta se origina en una experiencia individual dada por el investigado, es decir el análisis e interpretación de textos discontinuos y luego es puesta en práctica dentro de un grupo, para hacerlos participes de ese mismo interés voluntariamente aceptado. Por tanto, se espera la generación de una reflexión crítica sobre el plan de acción previamente desarrollado por el investigador y de las reflexiones concertadas en el grupo; en consecuencia, se busca que los resultados obtenidos en la investigación, aporten significativamente en el mejoramiento de la lectura crítica en los estudiantes.

En lo que se refiere a las fases de la investigación acción, Elliott (1991) define las siguientes:

- Planeación, conformada por la identificación de una idea general, comprende la descripción e interpretación del problema que hay que investigar. Exploración o planteamiento de las hipótesis de acción para cambiar la práctica.

- Acción, abarca la revisión del problema inicial y las acciones concretas requeridas; los instrumentos para tener acceso a la información. La puesta en marcha de manera controlada.
- Evaluación, análisis, interpretación y reflexión de los resultados y la revisión del plan general.

Comenzando con el desarrollo de la primera fase, es importante hacer énfasis en que el problema de investigación está basado en los resultados del Índice Sintético de Calidad (ISCE, 2016) del establecimiento educativo, ya que en la prueba de lenguaje en el componente progreso, evidencia un bajo rendimiento, aumentando el porcentaje en el nivel insuficiente y disminuyendo en el nivel avanzado.

En este orden de ideas las acciones encaminadas la descripción e interpretación del problema de investigación, se utilizó el diario de campo como instrumento para sistematizar la observación que se llevó a cabo para indagar sobre los conocimientos previos que poseen los estudiantes; además de profundizar en los sustentos teóricos de la investigación (caricatura y afiche). Con relación al desarrollo de la experiencia se aplicó una actividad diagnóstica que consistió en la interpretación de una caricatura y de un afiche, en donde los educandos identificaban elementos explícitos e implícitos y su posterior reflexión; dando a conocer su punto de vista sobre el contenido de las imágenes.

De esta forma los estudiantes del grado cuarto analizaron una caricatura donde se satiriza el modelo estético de la mujer actual representada en la vanidad; ellos describieron la imagen de una mujer que estaba pasada de peso, con el cabello alborotado, con la cara redonda, portando un traje largo y, que 
en su interior se sentía inconforme con su aspecto. En cuanto a los elementos implícitos los estudiantes describieron la imagen como una mujer vanidosa, orgullosa y presumida, llegando a la reflexión de que la belleza está en el interior del sujeto, es decir, cada persona lo demuestra con sus actos.

En el mismo sentido, los estudiantes del grado octavo analizaron un afiche publicitario denominado "No Más Bolsas" que correspondía a la imagen de una pareja, esta muestra al hombre elegantemente vestido y a la mujer mal vestida y ejecutando oficios cotidianos, en ella se critican irónicamente algunas celebraciones culturales y se cuestiona la sinceridad de las mismas, para el caso específico se toma la celebración del día internacional de la mujer. El propósito del afiche fue invitar al observador a no usar bolsas y recomienda como alternativas otros elementos de uso. A continuación se presenta la caricatura y afiche utilizado.
Los estudiantes reconocieron elementos explícitos tales como: el oficio que está haciendo la mujer, el cartel que colgaba del trapero con el que estaba aseando el piso, la mujer con rostro desgreñado y triste, el hombre más elegante vestido, con los ojos cerrados y aburrido. La intención del autor en el texto escrito "para que después no digas que no soy detallista", algunos estudiantes interpretaron el mensaje dejando ver al hombre en una posición machista. La expresión que maneja da a entender que no todos los hombres son felices celebrando el día de la mujer y, a nivel crítico y reflexivo los alumnos comentaron que las mujeres deben ser respetadas y amadas, que son tan importantes como los hombres porque son seres humanos a los que se deben respetar.

En el afiche alusivo al medio ambiente se observa un pingüino migrando a través de un desierto con elevadas temperaturas y un mensaje
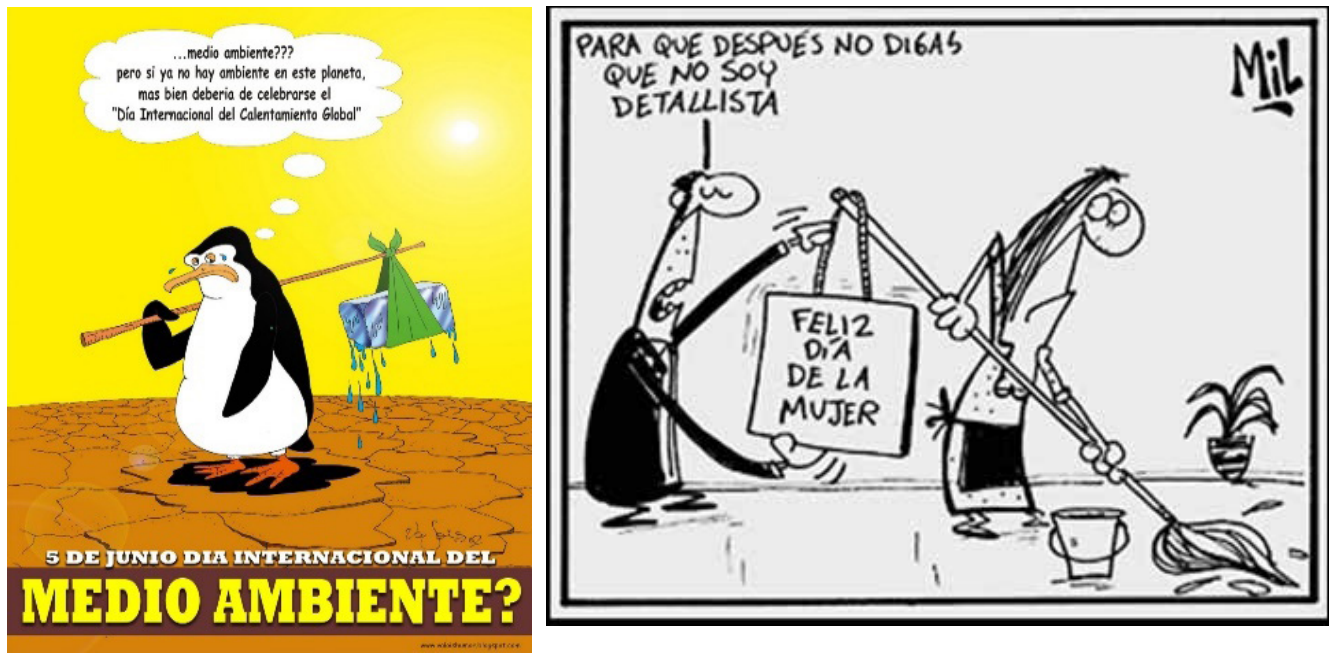

Gráfica 1. Afiche. Fuente. Día mundial

Del medio ambiente 5de junio 2014 
que cuestiona la celebración del día internacional del medio ambiente. Los estudiantes identificaron elementos explícitos en el afiche como, el tamaño de la letra en el título resalta la importancia del afiche; tres palabras que hablan del medio ambiente: reduzca, reutilice y recicle; el logotipo de una entidad ecológica. En cuanto a lo implícito un grupo de estudiantes habla de que el afiche da a conocer a las personas sobre el reciclaje, que muestra aspectos en los que el ser humano está fallando, que hay de otras formas de transportar los productos adquiridos en los almacenes, cajas, bolsas de tela y reutilizar bolsas plásticas; que se debe cuidar el planeta y no contaminarlo más. En el nivel crítico, asumen que el planeta necesita que lo protejan, caso contrario se destruirá, una de las maneras de ayudarlo es utilizando menos bolsas y tomar conciencia sobre el cuidado del medio ambiente.

Para finalizar a los estudiantes del grado $10^{\circ}$, se les presentó el mismo afiche, ellos lo interpretaron explícitamente resaltando las características de los personajes, la mujer no tiene cuello, no está feliz, tiene los ojos entre la nariz, tiene la boca cerrada; entre tanto el hombre tiene los ojos cerrados, con un tono burlesco manifestaron que la intención del texto era ridiculizar el papel de la mujer en su rol de ama de casa y no valorar el trabajo tan importante que desempeña en el hogar.

En lo correspondiente a la crítica los estudiantes expresaron que actualmente la mujer sigue siendo maltratada y en ocasiones humillada; sin embargo, manifiestan que, si la mujer se capacita y se profesionaliza, con una buena educación, se puede cambiar este aspecto tan marcado en la sociedad, que ella tiene un rol relevante para ser un agente activo dentro de la comunidad.

En cuanto al afiche alusivo al medio ambiente y el calentamiento global los alumnos identificaron los elementos explícitos como: el pingüino esta triste, se está yendo del norte, que se está sobrecalentando el planeta y se están descongelando los polos; desde la perspectiva inferencial se evidenciaron elementos implícitos como: el valor y el respeto hacia la naturaleza, una mofa por la celebración del día del medio ambiente, la destrucción de la naturaleza por parte de los humanos y, además aportaron opiniones sobre las posibles soluciones, que todo depende del actuar como seres humanos con la naturaleza.

Para concluir, en esta fase exploratoria la labor de las investigadoras excedió un poco los mecanismos de interpretación, ampliando las opiniones dadas por los estudiantes dejando de un lado una participación más significativa en su afán de cumplir cabalmente con el objetivo planeado dentro del ejercicio.

En la fase de acción el proyecto propone una serie de talleres que corresponden al análisis de elementos explícitos e implícitos de dos tipos de textos discontinuos: afiche y caricatura teniendo en cuenta el modelo pragmático de la relevancia de Sperber y Wilson, el cual será calificado con una prueba diagnóstica y una de salida 
aplicada a los grupos control con el fin de identificar el progreso, los alcances y las limitaciones que se presenten durante el desarrollo del proceso investigativo.

A través de la estrategia significativa, Díaz \& Hernández (2010) “el docente en su rol activo posibilitará” una combinación perfecta entre lo lingüístico y lo no lingüístico, para facilitar la elaboración de una interpretación ajustada al sentido del texto, de este modo la lectura aporta al mejoramiento de las habilidades que tienen que ver con la capacidad de relacionar la información del texto y los conocimientos que aporta el lector, para conseguir una comprensión profunda del texto, indispensable para que los estudiantes puedan "desenvolverse en el medio social, lo que constituye una pieza clave para el enriquecimiento intelectual, la adquisición de aprendizajes y el acceso a la cultura” (Gil, 2011, p.14).

Discusión de los resultados. Los resultados obtenidos luego de aplicar la prueba diagnóstica se enfocan principalmente a la comprensión de texto cuando se hace uso del afiche o la caricatura. Cuando se utiliza el afiche como técnica de comunicación se puede percibir que para los estudiantes es de gran importancia el texto en el afiche, por cuanto agrega y complementa la información o el mensaje que el autor quiere compartir; no obstante, la imagen favorece en el receptor una mejor idea de lo que las palabras señalan y por tal razón se siente identificado con lo cotidiano que las imágenes presentan.
El texto en una imagen puede ser necesario sin llegar a ser fundamental, hay imágenes que hablan por sí solas, pero puede ser motivo para emitir variadas interpretaciones de acuerdo con el observador, sin embargo, existen algunas que requieren una explicación verbal para lograr su objetivo.

Los estudiantes se limitan principalmente en aspectos visuales que son relevantes en el afiche, el color, el tamaño de la letra, la imagen utilizada, entre otros; estos aspectos no deben influir en la interpretación del mensaje del afiche; sin embargo, en algunas ocasiones el afiche puede ser interpretado de acuerdo con las necesidades del observador. Para el caso concreto los estudiantes lo perciben como si se tratara de una campaña que promueve el cuidado del medio ambiente, haciendo especial énfasis en dejar de utilizar bolsas plásticas a la hora de hacer compras; sin embargo, otros apuntan que se trata de una imagen cuyo mensaje es el calentamiento global; se percibe un entendimiento en cada una de las maneras de interpretar el mensaje.

Por su parte en el análisis de la caricatura se puede verificar la existencia de variadas interpretaciones, de acuerdo con los detalles recuperados por los estudiantes, es decir la interpretación dada algunas veces es adecuada, otras inadecuada, o simplemente se ubica en el intermedio de lo que el autor desea expresar. En el desarrollo de la actividad se percibe un abordaje de manera seria y con carácter en algunos estudiantes, otros por su parte lo hacen 
de manera sarcástica y otro tanto no le prestan atención alguna, esto se percibe al momento de la reflexión acerca del mensaje que quiere transmitir el autor.

\section{Conclusiones}

Este primer acercamiento al desarrollo del trabajo de investigación permitió indagar mediante una prueba diagnóstica con base en la lectura imágenes a partir de textos discontinuos como la caricatura y el afiche, con base en el modelo pragmático, el cual posibilitó tanto el análisis de sus elementos implícitos y explícitos como la reflexión del propósito e intención del mensaje. Llevó a los estudiantes a construir un significado desde su experiencia social y cultural. Desde esta apreciación se asoció la capacidad expresiva la cual se evidenció con la interpretación analítica y critica del estudiante, lo que aportó al proceso lector en la comprensión lectora.

La efectividad de la estrategia en su primer contacto con los textos discontinuos (caricatura y afiche) desde la perspectiva social y cultural, tuvo trascendencia en la reacción a lo leído, la emisión de juicios de valor, la combinación del pensamiento crítico con el creativo, aunado a la experiencia de conocimientos previos que enriquecieron el contexto del lector, lo que permitió finalmente la construcción de múltiples significados posibilitando una lectura crítica auténtica. No obstante, se requiere de la permanente práctica para combatir las dificultades en la comprensión lectora, nivel crítico intertextual, que se encuentran en proceso de mejoramiento.

En la comprensión lectora se requiere de un proceso lector dinámico, progresivo y rico en la movilización de conocimientos y experiencias para lograr desarrollar las capacidades del estudiante, con respecto a las habilidades perceptivas que favorecen el nivel de lectura crítica abordada desde el análisis e interpretación de textos discontinuos, los cuales propician establecer las relaciones existente entre diferentes elementos de un texto discontinuo y valoración de los contenidos presentes en las imágenes.

La caricatura y el afiche son textos discontinuos que llevan mensajes que permiten visibilizar un trasfondo de ideas intencionadas, puestas a disposición de la apreciación y valoración del lector, esté tendrá que construir un significado, proceso que implica identificar lo implícito y explícito, relacionarlo con los conocimientos y experiencias para poder transformarlo en un producto de sentido, de tal manera que en este proceso la comprensión lectora se lleva a cabo gradualmente, conduciendo al estudiante a la apropiación de enfrentar el mensaje críticamente.

Los módulos creados a partir de textos discontinuos utilizando caricaturas y afiches permiten fortalecer el proceso lector necesario para la comprensión lectora, considerando que el nivel de lectura crítica requiere la vigorización de la apreciación perceptiva y valorativa desde la perspectiva social y cultural del estudiante. 


\section{Referencias}

Acaso, M. (2009). La educación artística no son manualidades. Madrid, Catarata.

Baudelaire, B. (1984). Escritos sobre literatura, Barcelona: Bruguera.

Cassany, D. (2006).Aproximaciones a la lectura crítica, reflexiones. Revista de investigación e innovación del instituto universitario de ciencias de la educación.

Castro, J., Gómez, L., \& Prieto, A. (21016). Elementos para el análisis de imágenes para llegar a la lectura inferencial y crítica. Bogotá: Uniminuto.

Cifuentes, G. (2011). Diseño de proyectos de investigación cualitativa. Buenos Aires. Centro de publicaciones y material didáctico.

Eisner, E. (1995) Educar la visión artística. Barcelona, Paidós.

Elliot. (1993). La investigación-acción en educación. España: Morata

Gil, J. (2011) Hábitos lectores y competencias básicas en el alumnado de educación secundaria obligatoria Educación pp. 117-134 Universidad Nacional de Educación a Distancia Madrid, España

Hernández, G., \& Díaz, F. (2013). Una mirada psicoeducativa al aprendizaje: qué sabemos y hacia dónde vamos. Sinéctica, (40), 01-19.

Herrera, M. C. (2015). El manga, una herramienta didáctica en los procesos de lectura (Doctoral dissertation, Uniminuto).

Hutchinson, H. (1968). El afiche y sus estrategias. Madrid: Limusa

Inga, A. (2014). Estrategias cognitivas orientadas a los procesos de inferencia en el desarrollo de la lectura de alumnos del Vy VI ciclos de Educación Básica Regular. Investigación Educativa, p. 57-72.

ICFES, Instituto Colombiano para la Evaluación de la Educación (2012). Lectura Crítica Bogotá. D.C.

ICFES, Instituto Colombiano para la Evaluación de la Educación (2016). Lectura Crítica Bogotá. D.C.

León, F. (2006). Palabras en contexto. Bogotá: Libros \& libros.

PISA., (2012). Los textos discontinuos: ¿̨Cómo se leen? México: INEED

Reyes, H. (2016). Estrategias didácticas, mediación pedagógica y aprendizaje significativo. Revista Científica, Universidad Nacional Autónoma de Nicaragua 
Sandín, A. (2003). Investigación cualitativa en educación. $1^{\circ}$ edición. Madrid: McGraw Hill.

Solé, I. (1996). Estrategias de Lectura. Barcelona: GRAÓ

Sperber, D., \& Deirdre, W. (1994). La Relevancia. Madrid: Visor

Urrutia, M., \& García, J. (2013). Evaluación de la comprensión lectora en alumnos de primer y tercer curso de secundaria en Tenerife. Paideia N.o 53 (73-96). 